$\xi=-1$

\title{
X-Slotted circularly polarized antenna with parasitic patches
}

\author{
B T P Madhav, Habibulla Khan, B Sri Harsha, P Sai Kumar,M Lavanya, K Veena, M Venkateshwara Rao \\ Department of ECE, Koneru Lakshmaiah Education Foundation, Andhra Pradesh, India-522502 \\ *Corresponding author E-mail: btpmadhav@kluniversity.in
}

\begin{abstract}
A compact circularly polarized antenna having $\mathrm{x}$-slot in the parasitic patches have been proposed in this article. Four driven patches which are capacitively loaded with the help of the feeding loop and four parasitic patches which generate circular polarization because of the sequentially rotated structures are noticed in the proposed modal. With combination of the CP mode with the feeding loop we can observe the broadened axial ratio bandwidth. Comparative analysis has been observed for each side facing driven elements and side and edge facing parasitic elements with X-slot have been observed. The proposed antenna works at the bands of 5.04-5.83GHz and 6.34-6. $81 \mathrm{GHz}$ which works for WLAN application. The proposed modal and its iterations have been analyzed using ANSYS EM Software. The results show an enhanced impedance bandwidth of 22 percent and axial ratio bandwidth of over 15percent has been noticed in the proposed modal. A constant gain has been noticed all over the analyzed modals.
\end{abstract}

Keywords: Circular polarization (CP), Sequential phase, Parasitic patches, WLAN

\section{Introduction}

A broadband circularly polarized antenna having compact size is proposed in [1] and is designed with a loop feeding structure which will provide sequential phase, four driven patches and four parasitic patches. The axial ratio can be widened by adding all these patches. By simulating in HFFS, graphs are plotted between Reflection coefficient and frequency, Axial ratio and frequency, Gain and frequency, Radiation efficiency and frequency. Antenna gain is described as how well antenna converts input or given excitation into the radio waves moving in specified direction. A low RCS and high gain circularly polarized antenna with is proposed in [2] and is operated at a frequency range of $6 \mathrm{GHz}$ and reflection coefficient, gain and axial ratio bandwidth are calculated. S11 is one of the scattering parameters and it is a reflection coefficient and axial ratio is defined as the ratio between minor and major axis of polarization of eclipse. Dipole antenna means two poles or two conductors or two wires lying on the same plane of axes. A magneto-electric dipole antenna was proposed in [3]. That antenna structure consists of rotationally symmetric patches with two identical elliptical arcs that will function as respective magnetic dipole, and two vertical patches together with reflector acts as respective electric dipole. Omni directional antenna is a type of antenna which when it is excited the output radiation is distributed in all directions and it was used in applications such as GPS, Satellite and radar. One such antenna was proposed in [4] which consisting of two dielectric substrates, four shorting pins and one feeding pin. The radiation is realized at the azimuth plane. Impedance, right hand circularly polarized gain at azimuthal plane are determined. Dual band compact circularly polarized antenna is proposed in [5] which operates at $\mathrm{L} 2$ band $(1.215 \mathrm{GHz})$ and $\mathrm{L} 1$ band $(1.575 \mathrm{GHz})$ is designed to use in GPS Applications.
The impedance curve versus frequency is utilized to study the resonance point and radiation performance. Frequency - VSWR, Frequency - Radiation efficiency, Frequency - Gain and Axial ratio for both $\mathrm{L} 1$ and $\mathrm{L} 2$ bands are determined. The radiation performances were calculated in the anechoic chamber and both the RHCP and LHCP gains are observed and analyzed at certain frequency ranges. Single feed circularly polarized antenna with ultra wide band and front back ratio was proposed in [6] in which it is consisting of two orthogonally placed elliptical dipoles on both sides of the substrate. To analyze the performance of antenna the VSWR, Axial ratio, radiation pattern and antenna gain are determined. Both the RHCP and LHCP radiation pattern are obtained at a certain frequency and to analyze the ultra wide band characteristics, the electric field distributions are determined at $1 \mathrm{GHz}$, $1.8 \mathrm{GHz}$ and $2.6 \mathrm{GHz}$. Bow-tie antenna is also called as butterfly antenna is used for short range television reception.

A circularly polarized and cavity backed asymmetric crossed bowtie dipole antenna was proposed in [7] and reflection coefficient, frequency, axial ratio is determined. Cavity backed reflector is constructed using 5 copper plates. Impedance matching, and Axial ratio bandwidths are appropriately combining radiation from crossed dipole and asymmetric orthogonal slots. Compact circularly polarized antenna with 3 -db axial ratio bandwidth was proposed in [8] in which the s parameters, axial ratio and frequency graphs are compared and the minimum $3 \mathrm{db}$ AR beam width and half power beam width with various ground sizes are also determined. For perfect circularly polarized antenna the polarizations are equal (ratio of $1 \mathrm{db}$ or $0 \mathrm{db}$ ), whereas elliptical polarizations are somewhere in between. Usually the bandwidth/beam width of below $3 \mathrm{db}$ axial ratio is regarded as the useful operating range of circularly polarized antenna. The ka-band frequency range circular polarization microstrip antenna was proposed in [9] and 3-db axial ratio bandwidth, return loss was determined. The antenna consisting of four elements operating at ka band frequency range that is 
26 to $40 \mathrm{GHz}$ employs the sequential rotation method. Microstrip patch elements are used and symmetrically positioned with $\mathrm{L}$ shaped branches and a spatially rotated parallel or series feed network. The designed antenna can be integrated with millimeter wave active circuits and can find the applications in phased array radar and satellite communication systems.

A Novel design of dual band circularly polarized array antenna is proposed in [10] which consists of four truncated patches and one other patch on bottom layer. By this the impedance bandwidth lies in between 5.21 to 5.88 and 9.32 to $9.48 \mathrm{GHz}$ whereas the cp characteristic lies in 5.24 to 5.86 and 9.32 to $9.46 \mathrm{GHz}$. A dielectric resonator antenna with superstrate is designed and analyzed in [11] which the superstrate behaves as a polarizer to achieve circular polarization with impedance bandwidth of $73.67 \%$ at $5.81 \mathrm{GHz}$ operates in the frequency band of 3.68 to $7.96 \mathrm{GHz}$. A wide band circularly polarized open ended hexagonal slot antenna is proposed in [12] in which the open ended hexagonal slot is excited by asymmetrical feed line to achieve circular polarization. The antenna is designed with FR4 substrate and Impedance bandwidth ranges from 3 to $10.4 \mathrm{GHz}$ which is more prominent in UWB applications. A compact size multiband meta material-based antenna with circular polarization property is proposed in [13] in which the antenna operates at Bluetooth (2400 to $2484 \mathrm{MHz}$ ), Wi-Max, and c-band $(4-8 \mathrm{GHz})$. Linear to circular polarization conversion with wide band and wide-angle performances was presented in [14] with the help of multiband reflection mode linear to circular converters. Three single fed circularly polarized square patch antenna structure for wireless applications was proposed in [15] in which the antenna resonates from 1.5 to $1.8 \mathrm{GHz}$ by covering L-Band GPS and GSM 1800 band. Researchers proposed numerous models for linear and circularly polarized antennas [16-20].

\section{Antenna Design}

The proposed modal is designed using rogers RT DUROID 5880 material which is having relative permittivity of 2.2 and loss tangent of 0.0009 and having a dimension of $50 * 50 * 1$. 524.A trip which looks like a fan shaped has been placed to provide 90 degrees phase shift and a coaxial feeding has been placed to that fan shaped strip. Four square patches and four trunked square patches are placed to get the circular polarization. The proposed antenna has been optimized using ANSYS EM software. The geometric structures have been seen in the table 1 .

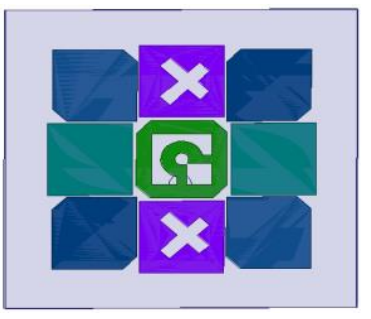

(a)Model-1

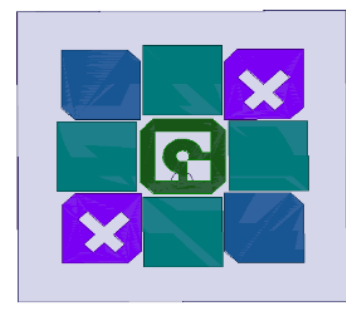

(c)Model-3

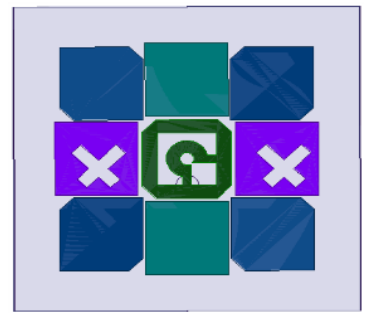

(b)Model-2

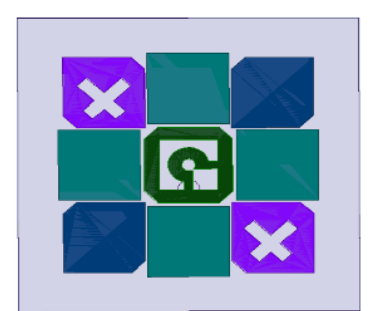

(d)Model-4

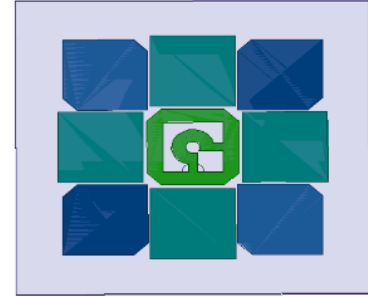

(d)Model-5

Fig:1 Iterations of the antenna model

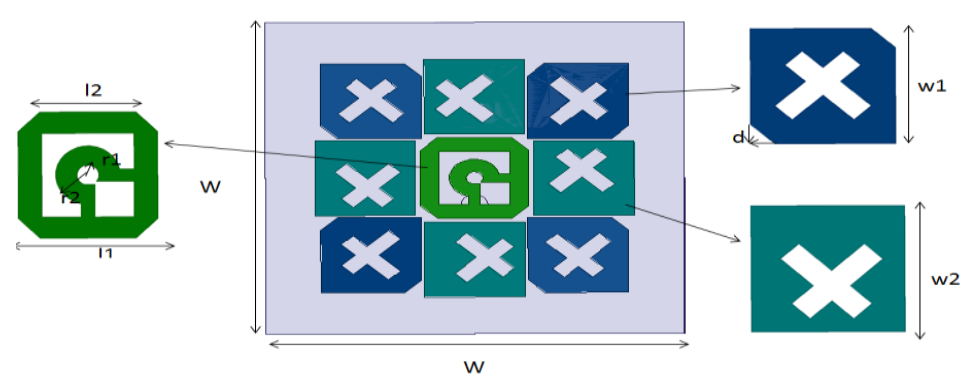

Fig:2: Layout of the proposed antenna

Table 1: Dimensions of the proposed antenna

\begin{tabular}{cc}
\hline Parameter & Value $(\mathrm{mm})$ \\
\hline w 1 & 50 \\
w2 & 12 \\
11 & 12 \\
12 & 12.9 \\
r1 & 8.5 \\
r2 & 1 \\
d & 3 \\
\hline
\end{tabular}

\section{Result Analysis}

As shown in figure-3 and 4, Return loss and Axial ratio are plotted against frequency of models 1 to 5 . Return loss and axial ratio is plotted against frequency for the proposed antenna which consists of $\mathrm{x}$-slots on all radiating patches in figure-3. From figure-1, Model-1 which consists of two opposite vertical $\mathrm{x}$-slots on patches, the return loss frequency is covered from 5.25 to $5.81 \mathrm{GHz}$ and the bandwidth is $0.56 \mathrm{GHz}$. Model-2 has two opposite horizontal patches got the return loss frequency from 5.4 to $6.6 \mathrm{GHz}$ and the bandwidth is $1.2 \mathrm{GHz}$. Model-3 and Model-4 have two opposite cuts diagonally whereas the return loss covers from 5.48 to 6.17 $\mathrm{GHz}$ and 5.46 to $6.34 \mathrm{GHz}$ with bandwidth of 0.69 and $0.88 \mathrm{GHz}$ respectively. Model-5 has no x-cuts on radiating patches and for it the return loss frequency is from 5.54 to $6.7 \mathrm{GHz}$ and bandwidth is $1.16 \mathrm{GHz}$. Simultaneously the Axial ratio plot against frequency was shown in figure- 2 in which the $3 \mathrm{~dB}$ bandwidth for model-1 is $0.21 \mathrm{GHz}$, for model- 2 is $0.35 \mathrm{GHz}$, for model- 3 is $0.19 \mathrm{GHz}$, for model- 4 is $0.17 \mathrm{GHz}$, and for model-5 is $0.2 \mathrm{GHz}$. The Return loss and Axial ratio plot against frequency for the proposed antenna was shown in figure- 3 in which the return loss covers two bands from 5.04 to $5.83 \mathrm{GHz}$ and 6.34 to $6.81 \mathrm{GHz}$ with a bandwidth of 0.79 and $0.37 \mathrm{GHz}$ respectively and with a notch in the middle of these two bands. The axial ratio almost covered the band that was covered by return loss with a $3 \mathrm{~dB}$ bandwidth of $0.36 \mathrm{GHz}$. 


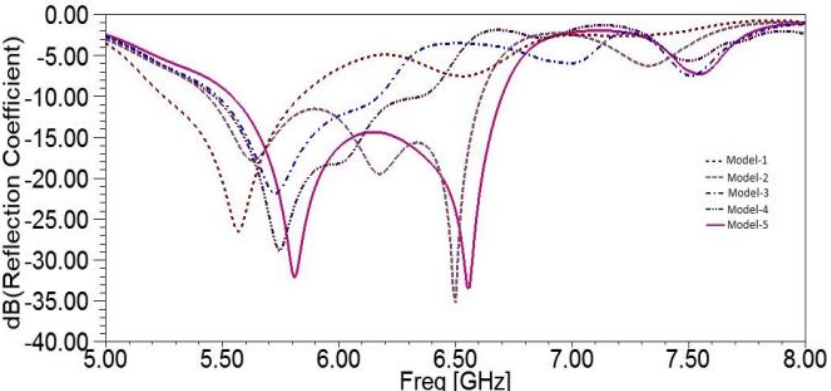

Fig 3: Return loss v/s Frequency graphs for iteration 1 to iteration 5.

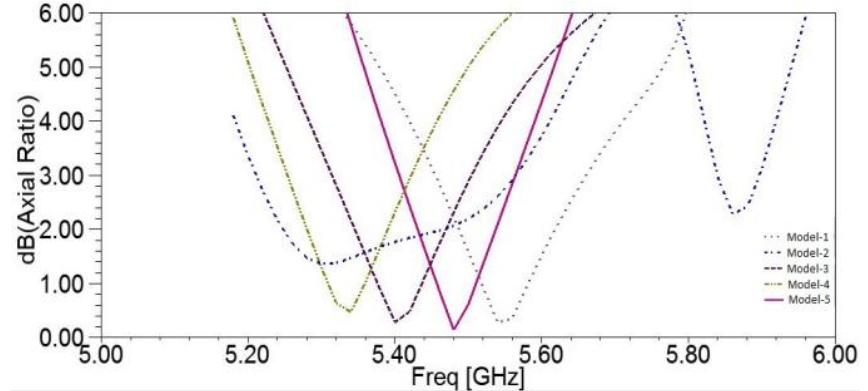

Fig 4: Axial ratio v/s Frequency graphs for iteration 1 to iteration 5.

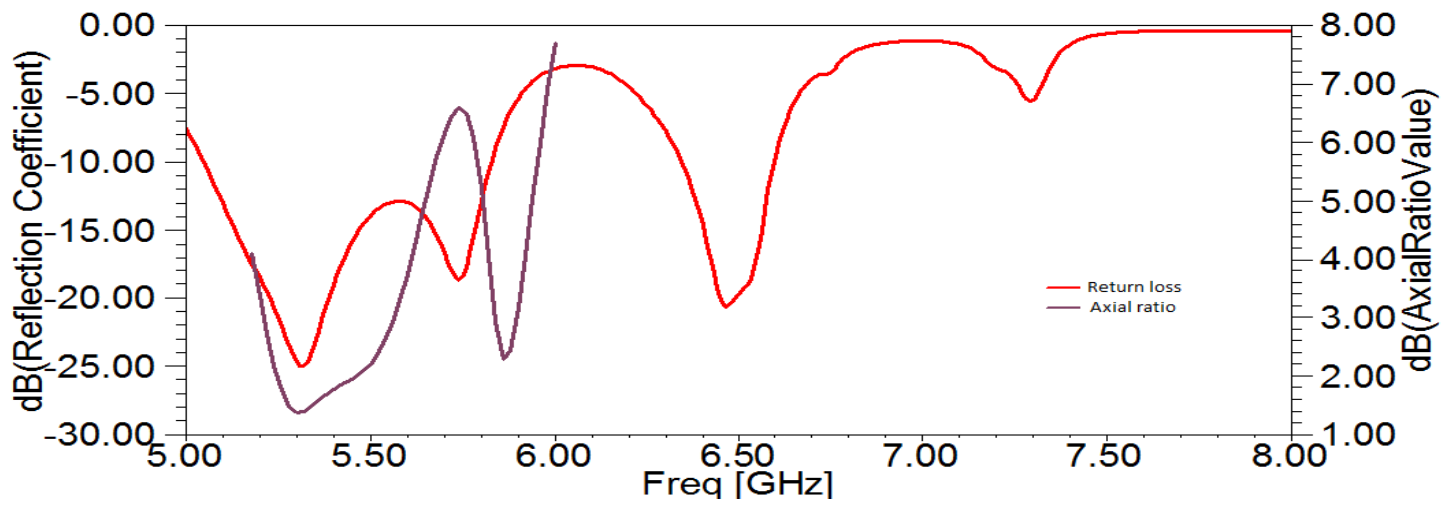

Fig5: Return loss and Axial ratio v/s Frequency graph for proposed model

Table 2: Antenna Return loss bandwidth

Table 2: Antenna Return loss bandwidth
\begin{tabular}{|c|c|c|c|}
\hline s.no & Model & $\begin{array}{c}\text { Frequency Cov- } \\
\text { ered(GHz) }\end{array}$ & Bandwidth(GHz) \\
\hline 1 & Model-1 & $5.25-5.81$ & 0.56 \\
\hline 2 & Model-2 & $5.4-6.6$ & 1.2 \\
\hline 3 & Model-3 & $5.48-6.17$ & 0.69 \\
\hline 4 & Model-4 & $5.46-6.34$ & 0.88 \\
\hline 5 & Model-5 & $5.54-6.7$ & 1.16 \\
\hline 6 & Proposed & $5.04-5.83$ & 0.79 \\
& Model & $6.34-6.81$ & 0.37 \\
\hline
\end{tabular}

Table 3: Antenna axial ratio bandwidth

\begin{tabular}{|l|l|l|l|}
\hline s.no & Model & $\begin{array}{l}\text { Frequency Cov- } \\
\text { ered(GHz) }\end{array}$ & AR Bandwidth(GHz) \\
\hline 1 & Model-1 & $5.45-5.66$ & 0.21 \\
\hline & & & \\
\hline 2 & Model-2 & $5.21-5.55$ & 0.35 \\
\hline 3 & Model-3 & $5.31-5.50$ & 0.19 \\
\hline 4 & Model-4 & $5.25-5.42$ & 0.17 \\
\hline 5 & Model-5 & $5.4-5.6$ & 0.2 \\
\hline 6 & $\begin{array}{l}\text { Proposed } \\
\text { Model }\end{array}$ & $5.25-5.61$ & 0.36 \\
\hline
\end{tabular}

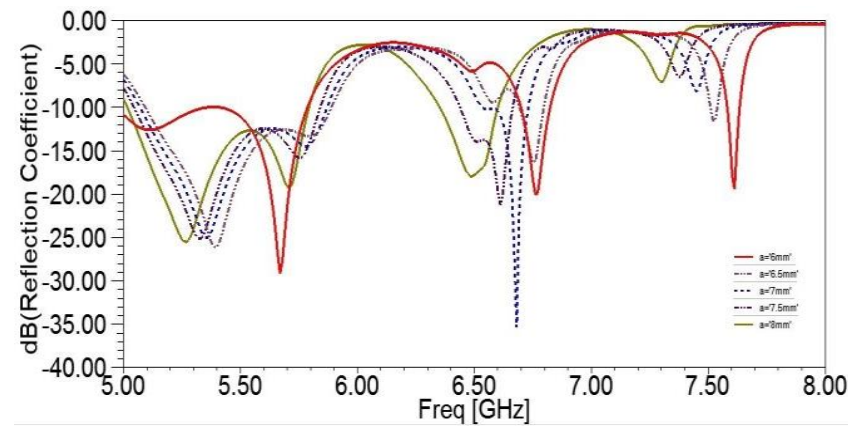

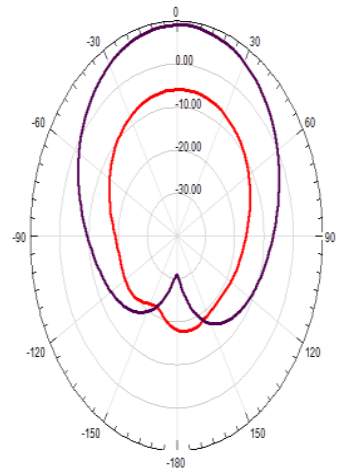

(a)

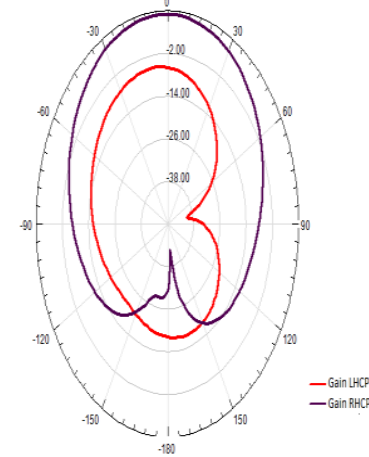

(b)
Figure 8(a) : Gain LHCP and RHCP at E-Plane at 5.3GHz (b)Gain LHCP and $\mathrm{RHCP}$ at $\mathrm{H}$-Plane at $5.3 \mathrm{GHz}$

Fig 6: Parametric analysis by varying parameter slot width. 


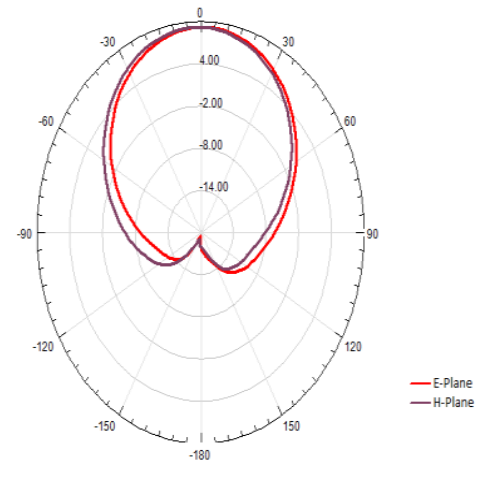

(c)Total Gain at $5.32 \mathrm{GHz}$
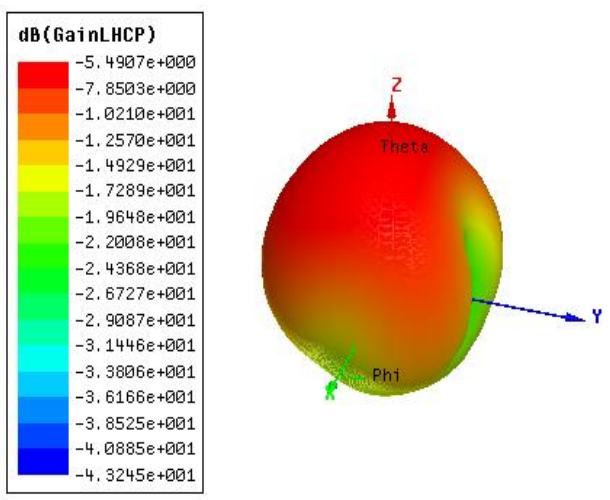

(a)
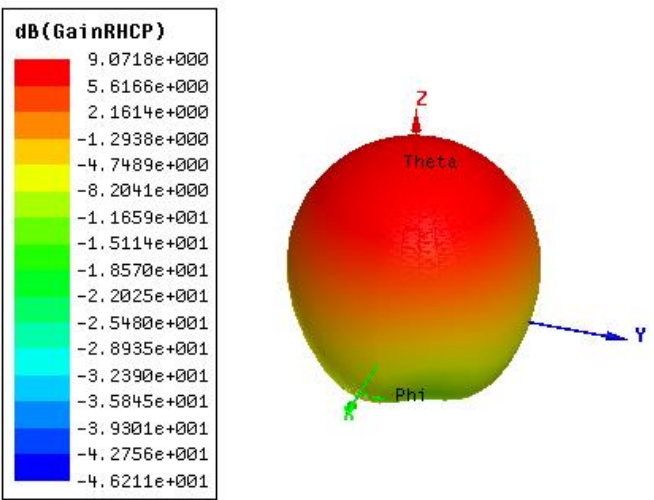

(b)

Figure 9: (a) Gain LHCP and (b) RHCP 3Dpolar plot

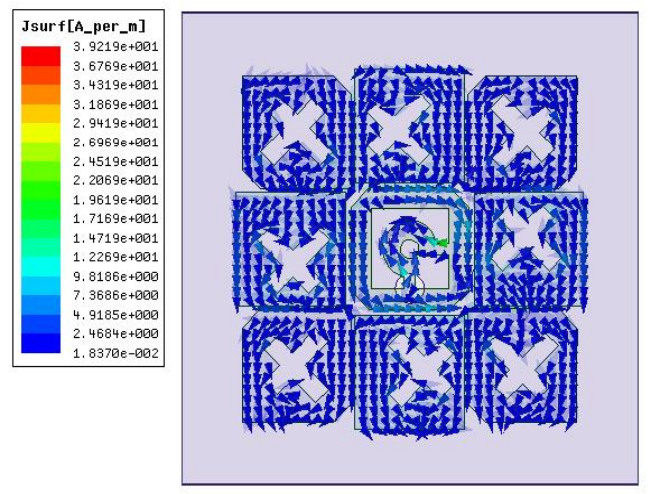

(a)

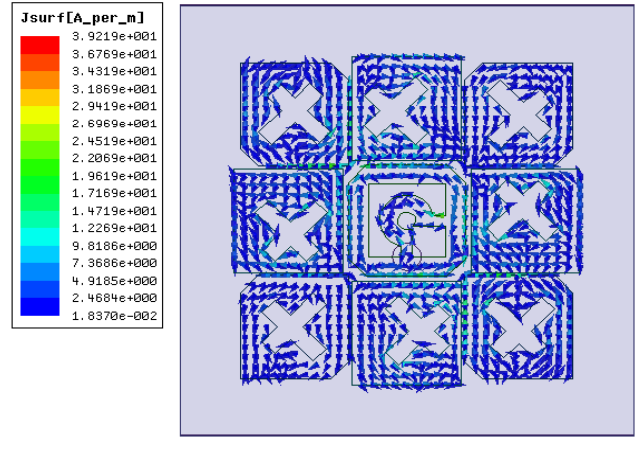

(b)

Figure 10(a): Current distribution at $5.32 \mathrm{GHz}$, (b) Current distribution at $6.47 \mathrm{GHz}$

\section{Conclusion}

A compact circularly polarized antenna having X-Slots has been analyzed iteration wise. A two-sided $\mathrm{x}$-slot for each iteration have been observed. Later for all iteration the $\mathrm{x}$-slots has been incorporated and it gets a wider impedance bandwidth of over 22 percent and higher axial ratio of 15 percent has been achieved. The proposed antenna works at the band of WLAN application. In addition to that a flat gain response and a good radiation efficiency has been noticed in the proposed antenna.

\section{Acknowledgements:}

The authors deeply express their gratitude to ALRC Research Centre, Department of ECE, K L University for their encouragement during this work. Further, we express our gratitude to DST through ECR/2016/000569, FIST SR/FST/ETI-316/2012 and EEQ/2016/000604.

\section{References}

[1] Zhang, B., Zhang, Y. P., Titz, D., Ferrero, F., \& Luxey, C, A.(2013) circularly-polarized array antenna using linearlypolarized sub grid arrays for highly-integrated $60-\mathrm{GHz}$ radio. IEEE Transactions on Antennas and Propagation, 61(1), 436-439.

[2] Jia, Y., Liu, Y., Gong, S., Zhang, W., \& Liao, G. (2017) A LowRCS and High-Gain Circularly Polarized Antenna with a Low Profile. IEEE Antennas and Wireless Propagation Letters, 16, 2477-2480.

[3] Kang, K., Shi, Y., \& Liang, C. H. (2017) A wideband circularly polarized magneto-electric dipole antenna. IEEE Antennas and Wireless Propagation Letters, 16, 1647-1650.

[4] B T P Madhav, T Venkateswara rao, T Anil Kumar. (2018) Design of 4-Element Printed Array Antenna for Ultra-Wideband Applications. International Journal of Microwave and Optical Technology, Vol.13, No.1, pp 8-17.

[5] S. S. Mohan Reddy, B. T. P. Madhav, B. Prudhvinadh, K. Aruna Kumari, M. V. S. Praveen, M. Hemachand, E. Mounika. (2018) Arc-Shaped Monopole Liquid-Crystal Polymer Antenna for Triple-Band Applications, Lecture Notes in Electrical Engineering, ISSN: 1876-1100, Vol 471, pp 797-806, doi.org/10.1007/978981-10-7329-8_82.

[6] B T P Madhav, D S Ramkiran, K Manikanta Varma, Y Sireesha. (2017) A CPW Fed Serrated Fractal Antenna for UWB Applications, International Journal of Pure and Applied Mathematics, Volume 117, No. 16, pp 679-683.

[7] Raghava Yathiraju, P Pardhasaradhi, B T P Madhav. (2017) Circular Meandered Defected Ground Structured Stable Gain Monopole Antenna for LTE Applications, International Journal of Pure and Applied Mathematics, Volume 117, No. 18, pp 113118.

[8] M Lavanya, K V Prasanth, B T P Madhav. (2017) Compact Printed Elliptical Slotted Antenna for Multiband Applications, 
International Journal of Pure and Applied Mathematics, Vol 117, No. 19 , pp 253-258.

[9] S. S. Mohan Reddy, P. Mallikarjuna Rao, B. Prudhvi Nadh, B. T. P. Madhav. (2018) Design and Analysis of Compact Circular Half-Ring Monopole Antenna with DGS, Smart Innovation, Systems and Technologies, Vol 77, pp 221-231.

[10] Vamseekrishna Allam, B. T. P. Madhav. (2018) Defected Ground Structure Switchable Notch Band Antenna for UWB Applications, Smart Innovation, Systems and Technologies, Vol 77, pp 139-145.

[11] G Jyothsna Devi, B T P Madhav. (2017) Reconfigurable Mimo Antenna For 5G Communication Applications, International Journal of Pure and Applied Mathematics, Vol 117, No. 18, pp 89-95.

[12] Kosuru Murthy, Kodidasu Umakantham, Korlapati Satyanarayana Murthy, B T P Madhav. (2017) Reconfigurable Notch Band Monopole Slot Antenna for WLAN/IEEE-802.11n Applications, International Journal of Intelligent Engineering and Systems, ISSN: 2185-3118, Vol 10, No 6, pp 166-173.

[13] Abdul Rahiman Sheik, Kalva Sri Rama Krishna, B.T.P. Madhav. (2017) Circularly Polarized Defected Ground Broadband Antennas for Wireless Communication Applications, Lecture Notes in Electrical Engineering, ISSN: 1876-1100, Vol 434, pp 419-427.

[14] D.S. Ramkiran, P. Siddaiah, B.T.P. Madhav. (2017) BandNotched Circular Serrated Wideband Antenna, Lecture Notes in Electrical Engineering, ISSN: 1876-1100, Vol 434, pp 555-563.

[15] S.S. Mohan Reddy, P. Mallikarjuna Rao, B.T.P. Madhav, B. Prudhvi. (2017) Design and Analysis of Circular Notch Band DGS Monopole Antenna, Lecture Notes in Electrical Engineering, ISSN: 1876-1100, Vol 434, 2017, pp 409-417.

[16] B.T.P. Madhav, D.S. Ram Kiran, V. Alekhya. (2017) An Asymmetric Liquid Crystal Polymer Based Fractal Slotted UWB Monopole Antenna with Notch Band Characteristics, Rasayan Journal of Chemistry, ISSN: 0974-1496, Vol 10, No 3, pp 852860.

[17] Ramkiran, B. T. P. Madhav, T. Anilkumar. (2017) Pentagonal Shaped Koch Fractal Monopole Slot Antenna for Multiband Applications, ARPN Journal of Engineering and Applied Sciences, ISSN 1819-6608, Vol. 12, No. 15

[18] P. Poorna Priya, Habibulla Khan, B T P Madhav. (2017) Defected Ground Structure Circularly Polarized Wideband Antennas for Wireless Communication Applications, Journal of Advanced Research in Dynamical and Control Systems, Vol 9, No 18, pp 122-130.

[19] P Poorna Priya, Habibulla Khan, B T P Madhav. (2017) Circularly Polarized Single Layer Capacitive Coupled CPW Fed Micro Strip Patch Array with Gap Coupled Resonators, International Journal of Pure and Applied Mathematics, Volume 117, No. 18, pp 23-30.

[20] Vinay Balusa, V S K Pavan Kumar, B T P Madhav. (2015) Aperture Coupled Feed Circularly Polarized Antenna", Spaces, IEEE, pp 240-244. 